\title{
INFORMATION TECHNOLOGY, INNOVATION AND HUMAN DEVELOPMENT: HOSPITAL INFORMATION SYSTEMS IN AN INDIAN STATE
}

\author{
Sundeep Sahay and Geoff Walsham
}

\begin{abstract}
This paper addresses the topic of how innovation based on information and communication technologies (ICTs) can contribute to human development. A theoretical framework is developed in two stages. Firstly, ICT-based innovation is conceptualised as involving technological, social and institutional innovation. Secondly, Sen’s capability approach is drawn on to theorise how such innovations can contribute to human development. The theoretical framework is used as a basis to explore a rich case study of the development and use of a hospital information system within the public sector of the State of Himachal Pradesh in India. The paper analyses both the potential that the system has to promote positive development outcomes in the State, but also the challenges which constrain that impact. Three human development themes are identified and discussed: strengthening processes to include the disadvantaged; empowering the patient; and making communal voices count. Finally, it is argued that the theoretical approach in the paper may have applicability in other contexts where ICT-based innovations are aiming to support human development outcomes.
\end{abstract}

Keywords: ICTs, innovation, human development, capability approach, health, India Accepted for publication in the Journal of Human Development and Capabilities 


\section{INTRODUCTION}

There has been interest for many years in the use of ICTs in developing countries (e.g. Bhatnagar and Bjørn-Andersen, 1990) but recent years have seen a major upsurge in activity in information and communication technology for development (ICT4D). New technologies such as the mobile phone, cloud hosting and social networking have played a part in this, and also renewed interest in the 'bottom of the pyramid' (Prahalad and Hammond 2002), relating to the purchasing power of the four billion or so people in the world with incomes in the lowest category. However, Heeks (2006) noted that the term 'development' itself remained undefined in much of the ICT4D literature and, in a later article (Heeks 2010) he argued the need for more theory-based evidence about the impact of ICTs on development. In a related way, Avgerou (2010) suggested that a major theoretical challenge for the ICT4D field was to strengthen its capacity to associate ICT-based innovation with socio-economic development.

This paper takes up the challenge to theorise the links between information technology, innovation and development in two stages. Firstly, we consider the nature of ICT-based innovation, and we argue that it is not merely technological innovation. Social and institutional innovation are needed if the technological innovation is to be effective in a complex local context. The second strand of our theoretical approach addresses the question of 'innovation for what?' or, more precisely, how can ICT-based innovation contribute to human development. In order to address this question, our theoretical framework will draw on the work of Amartya Sen and his 'Capability Approach'.

We will use the theoretical framework as a basis to explore an extensive and rich case study of hospital information systems in the state of Himachal Pradesh in India. We will discuss both the potential that the hospital information systems have to promote positive development outcomes, but also the challenges which constrain that impact. We will thus develop some 
implications for enhancing the contributions of the ICT-based innovation to human development.

The rest of the paper is organized as follows. In the next section we develop our theoretical framework for ICT-based innovation for human development. We then outline our research methods and describe the case study of hospital information systems in the chosen Indian state. We next analyse our case study through the lens of the theoretical perspective described earlier. We consider both the nature of ICT-based innovation in this context and also the contribution of the innovation to human development. Finally, we draw some conclusions from our research and identify opportunities to build on the work in the future.

\section{THEORETICAL PERSPECTIVE}

Our theoretical perspective is developed in this section in three steps. Firstly, we discuss the nature of three different kinds of innovation. Next we consider how such innovations can contribute to the goal of human development. Finally, we bring these ideas and concepts together in our overall theoretical framework.

\subsection{Technological, social and institutional innovation}

ICT-based innovations clearly involve technological innovation as their starting point. However, in order to be effective, social innovation is often essential. For example, affordability constraints are vital in order to provide products and services which are within the reach of the poor. An example is the M-Pesa application in Kenya, using mobile phones and a socially innovative network of agents to bring banking facilities to the poor (Moraczynski 2009). M-Pesa also involved institutional innovation, tackling the constraints 
which arise through established institutions of various types such as political, legal and technological environments. In some contexts, in addition to the constraints of existing institutions, there may well be institutional voids making it necessary to create new institutional structures from scratch.

Bhatti (2012) notes that the intersections between technological, social and institutional innovations are of particular importance. He provides an illustrative example of the Rickshaw Bank project in India. This enabled rickshaw drivers to own rather than rent rickshaws. Technological innovation was used to redesign the rickshaws, social innovation to restructure the prevalent practice of renting to owning, and institutional innovation to license and recognize rickshaw owners as formal contributors to the local economy. Bhatti argues that any of the three innovations in isolation would not have been likely to succeed but, by combining the three, more than 30,000 rickshaw drivers have benefitted.

A further example of the intersection of the three types of innovation, using a case study from the health sector, is provided by Braa and Sahay (2012) on the reform of the national level health management information system (HMIS) in India. Institutionally, the reform sought to integrate the different vertical health programmes, such as immunization and disease surveillance, with the routine HMIS. Historically, these programmes have existed in isolation, each with their own information systems, heightening the problem of fragmentation. Technologically, the Indian states were encouraged to adopt a web-based open source software system, so that they did not get locked into proprietary systems and possessed the flexibility to grow and adapt to changing health system information needs. This web based system also enabled peripheral health facilities to enter data into the central system, thus making the health status of their (previously hidden) catchment population visible to others. This had significant social implications in a country with a large rural population residing in 
inaccessible and underserved areas. Innovation took place because of the intersection between the institutional, technological and social domains. There was the institutional mandate to address existing fragmented systems, which was made possible technologically by the webbased open source software, which could also be accessed by peripheral health facilities, allowing the health condition of rural populations to become visible to the decision makers in the national ministry.

\subsection{ICT-based innovation for human development}

So ICT-based innovation often requires technological, social and institutional innovation at the same time. However, our paper is concerned with innovation for human development so we also need to theorize what we mean by this latter term. One theory of development which has received much attention in recent years is the capability approach (CA) developed by Amartya Sen (Sen 1999). Sen is an economist by background, but the CA is a much broader approach than is typical in economic theories of development that focus solely on issues such as income, expenditure and growth models. In contrast, the CA focuses on the 'freedom' which individuals have to lead the lives that they value. Thus, we should look at poverty not solely as low levels of income, but impoverished lives, namely the deprivation of freedom to undertake activities that a person might wish to choose. Two major constituents of the CA are ‘functionings' and 'capabilities'. Functionings refer to realized achievements and fulfilled expectations for the individual, whereas capabilities refer to effective possibilities for achievements. Sen does not apriori specify what these capabilities and functionings are, since he argues that different capabilities and functionings may be relevant in different contexts.

Little mention is made by Sen of the role of ICTs but a number of researchers have recognized the potential of the CA to theorize the impact of ICTs on development. For 
example, Zheng (2009) is a conceptual article which argues that the CA provides a different and wider 'space' to assess e-development than traditional economic theories. Hatakka and Lagsten (2012) operationalise the CA using a case study of students from developing countries and their use of internet resources. Smith et al (2011) provide evidence that mobile phones are making substantive contributions to capabilities and freedoms in economic, social and governance spheres. Zheng and Walsham (2008) use case studies of health systems in South Africa and China linking the use of information or lack of it to various freedoms or to capability deprivation.

An interesting and well-developed example of the application of the CA to the domain of ICTs for development is the work of Kleine (2010, 2013). She set the CA in a choice framework with four elements: agency, structure, dimensions of choice, and development outcomes. Kleine’s work is consistent with that of Sen, emphasizing the importance of choice itself as a primary development outcome with a range of secondary outcomes which may or may not be relevant in specific contexts. These may include, for example, easier communication, increased knowledge, healthier environment, increased income, more voice, more autonomy, etc.

\subsection{Theoretical Framework}

The theoretical framework which we will use to analyse our case study combines use of the capability approach from the work of Sen and followers augmented by concepts of ICT-based innovation described earlier. The framework draws, firstly, from an adapted version of Robeyns’ (2005) ‘stylised non-dynamic representation of a person’s capability set and her social and personal context'. The basic level in Robeyns' framework is that of the utilization of goods and services in order to enhance capabilities and, in turn, functionings. For example, 
goods and services will draw on inputs such as ICTs, finance and manpower. Capabilities are the freedoms or valuable opportunities which people have to lead the kinds of lives they wish to lead (Robeyns 2005). Functionings concern actual outcomes rather than capabilities. With respect to health systems, such outcomes could involve better treatment brought about by providing patients with the capability to be involved in their treatment choices. It is important to note that this level of analysis concerns an individual. Although resources may be communal to some extent, their conversion into capabilities and functionings is personspecific. For example, the provision of a written description of a planned treatment may be provided by a new information system but the value of this will be reduced if the individual is illiterate, or is unable to read and understand the language of the document.

A second level of analysis in Robeyns' framework concerns constraints and opportunities which affect and influence the conversion from goods and services to capabilities and functionings. These conversion factors include personal characteristics such as literacy as noted above but also mental and physical conditions, gender and educational levels. Social conversion factors include social norms such as the role of women, and social institutions such as legal systems. Institutional conversion factors include power structures such as hierarchies. These conversion factors influence everyone in principle, but the impact will be different dependent on individual characteristics and the role of that individual. For example, in the context of health systems, different roles include that of patient, nurse, doctor or health administrator.

So where do ICT-based innovations fit into the picture? These involve, as described earlier, various forms of technological, social and institutional innovation. Their potential influence is multi-faceted. Firstly, at the individual conversion level, the innovation may provide new 'capability inputs' such as computers and information systems leading to different 'goods and 
services' being available to the patient such as a computerised treatment record. However, the innovation may also influence the constraints and opportunities at the second level of analysis. For example, it may provide the opportunity to enhance patient rights through an entitlement to a written (computer-generated) copy of their health record. The innovation may also change the impact of conversion factors on particular individuals. For example, a decision to include a local language version of a patient record may affect a whole group of patients and their ability to utilize resources to enhance their capabilities and, in turn, their functionings.

This brief description of our theoretical framework will be augmented in the rest of the paper when we apply the framework to our case study of hospital information systems. However, it is worth noting that the framework addresses some interesting points raised in some recent literature on innovation, the capability approach and the role of technology. For example, Hartmann (2012) argues that innovation creates an evolving dynamic context within which human capabilities are changed or extended. Thus innovation can be seen to be adding a dynamic element to standard capability analysis as we have shown in our framework. With respect to the role of technology in such processes, Ziegler et al (2013) argue the need for capability sensitive design in technological innovation (direct factors) but also in indirect conversion factors such as institutions. Our framework in this paper considers innovation to involve both technological and institutional change. Oosterlaken (2011) also sees an important role for technology in expanding human capabilities. However, drawing from the literature on actor-network theory (see, for example, Latour 2005), Oosterlaken argues that we need to see technical artefacts in their networks of interdependencies with people, other artefacts and social structures. The framework in our paper reflects this concern to integrate technology with broader social and institutional structures. 


\section{RESEARCH METHODS}

The research described in this paper is part of a larger project concerned with the design, development and implementation of a hospital system in an Indian state. The first author of this paper has been involved with the project from its initiation in 2009 until the present day, and has made more than twenty visits to the different hospital sites: supporting processes related to the study of requirements; interacting with the project team on design and capacity building efforts; and meeting with officials of the State to evaluate progress and discuss strategy. In carrying out these activities, many data have been generated on the history of the project implementation and documented in minutes of meetings, email correspondence, progress reports and project evaluations. These data have informed the case description and analysis reported on later in the paper.

By 2015, the hospital information had been deployed in all 20 district and sub-district hospitals in the State, and a specific piece of research was carried out to understand issues related to the impact of the system on patients, the end beneficiaries. Seven hospitals were chosen for the field study in which the information system had been in use for at least 6 months and where most of the system modules were fully functional. A questionnaire was developed with a checklist of questions designed to probe patients about their experiences in the hospital, and whether they felt the system provided them with better care, a more positive experience, and with more choices to pursue their well-being. The questionnaire is attached as Appendix 1.

The first author of this paper worked with and trained a member of the Indian nongovernmental organisation (NGO) to interview patients in a particular hospital using this checklist. The NGO member then carried out patient interviews at the other six hospitals 
chosen for the study. A total of 63 patients were interviewed during this process. The data collected by this research process were primarily qualitative in nature involving patient opinions and perceptions. This was supplemented with observations of patient-doctor and staff interactions, and some discussions with the hospital staff. The data were analysed into important themes and issues and these fed into the case analysis which will be reported on later in this paper.

\section{CASE STUDY: HOSPITAL INFORMATION SYSTEM IN AN INDIAN STATE}

In line with the theoretical perspective presented earlier, the case context described below emphasizes the constraints and opportunities experienced with respect to the hospital information system being developed and implemented. Following this, we provide a brief overview of the initiation of the complex and extensive case study. We then draw upon the interviews carried out with patients and others to understand what have been some of the impacts of the system.

\subsection{Case context: constraints and opportunities for the hospital information system}

The case study is based on a large and ongoing project to design, develop, implement, and support a hospital information system (we call HospIS) within a network of all the 20 district and sub-district hospitals in the public health sector of the Indian state of Himachal Pradesh. The state is located in hilly terrains spanning 55,000 sq km and hosting a population of 6.08 million, a population density of 109 per sq $\mathrm{km}$ as contrasted to the national average of 312 . The geographical terrain and spread out population distribution entails both constraints and 
opportunities. The hilly terrain and long distances for travel to the health facilities are constraining in terms of access to care. There is a dearth of private sector health care providers in the state, which results in heavy patient loads in resource-constrained public facilities. These conditions, however, also create opportunities as the reform of the health sector is a central focus of the state government's political agenda. This has helped to create an enabling environment for the state to strengthen public health systems and enhance the use of ICTs, as it provides them with strong political legitimacy. Drèze and Sen (2013) have described Himachal Pradesh as one of the few states in India that have achieved wellfunctioning public services, including health and education.

Like other populations that are growing in development status, India is dealing with new health challenges coming from non-communicable diseases such as heart disease and diabetes, while also needing to address traditional public health challenges such as diarrhoeal diseases amongst children below 4 years, and anaemia and iron deficiency amongst women of reproductive age. Given this double disease burden of both "new” and traditional primary health care related challenges, Himachal Pradesh has needed to strengthen both primary care amongst the rural population and also the more specialized secondary care for diseases such as those related to the heart, TB and diabetes within the hospital structure. Additionally, they have tried to strengthen the referral linkages between the primary and secondary level facilities in district hospitals to enable continuity of care for patients. Strengthening of health information systems has been key in these efforts. In this paper, we focus on reforms specifically related to hospital information systems, including efforts to transform largely manual systems to a computer based one, and strengthening capacity and infrastructure to deal with these new modes of working. 
A district hospital is typically 250-300 bedded, serves as the referral institution for all health facilities, called subcentres and primary health care units, with facilities for surgeries, inpatients, blood transfusions, and other forms of specialist care. District hospital facilities typically cater to a catchment population of 1.5 to 2 million people, which translates as an average daily outpatient load of about 750-800. Like the situation in other Indian states, and also most developing countries, hospitals are typically under-staffed and poorly resourced, including relating to the IT systems. Given the multi-faceted and interlinked nature of services provided by the hospitals, a supporting hospital information system needs to cater to various clinical services (the different outpatient and inpatient departments), administration functions (registration, billing, stocks, drugs), and support services (such as laboratories, radiology, and pharmacy). These different modules need to be linked with each other to provide patients with integrated and continual care.

Historically, governments and donors have focused on strengthening health management information systems for the primary health sector, while (district) hospital information systems have been largely neglected. Braa and Sahay (2012) attribute this neglect to district hospitals being complex sites where showing results is very resource intensive and challenging. For example, the entire health management information system of a district could potentially be managed with one computer, while in just one hospital facility there may be the need for 10-15 computers to operationalize a hospital information system.

In summary, the existing context is pregnant with various constraints and opportunities with respect to the deployment of hospital information systems. Constraints include limited resources, high patient loads, poor infrastructure, complexity of hospital services and lack of prior history with IT systems. Opportunities include the political will to change, relative 
absence of prior computerization, and increasing acceptance of the central role of IT in health sector reforms.

\subsection{Initiation of the HospIS project in Himachal Pradesh}

In order to implement the hospital information system, Himachal Pradesh (HP) approached an Indian non-governmental organization (INGO) which was already working with them to support their HMIS. INGO specialized in open source based systems, had both public health and technical expertise, and was grounded in a strongly participatory approach to systems development. A first step to operationalize the project was for HP to develop a contracting mechanism with INGO. Typically, such projects in the public system required a tender process to be adopted. But since this would involve a long drawn-out process, and be potentially subject to external interference, HP decided to develop a tripartite arrangement involving themselves, INGO and a quasi-government technical support agency with whom INGO was already partnering with in other projects. The involvement of this agency, being quasi-government, removed the need for a tendering process.

Once the contracting mechanisms were put in place, a first step in the project was for INGO and HP to dialogue on system scope. INGO emphasized a focus on the "core” modules, related to clinical care, hospital administration and management, and the scope was reduced to 10 essential modules from an initial set of 20 identified by the state. Further, it was agreed that the application would be developed on an open source platform to eliminate licensing costs and for the state to keep relative control of the source code to allow for future expansion.

A hospital in the state capital was selected to be the reference one, where the system in its entirety of 10 modules would be designed and implemented, and then be taken in an incremental manner to 19 other hospitals. By mid-2010, the 10 modules were made 
operational and implementation initiated in the reference hospital. Around then, the process to scale it to other hospitals was started. By 2015, all the 20 hospitals had been covered.

A key support role in the scaling process was that of a local data entry firm which, while starting off by performing data entry functions for registration and billing, was slowly mentored and coached by the INGO team to learn more broadly about the system. They started to provide support on other functions such as training in all hospitals, carrying out routine server support and other trouble shooting functions.

The uptake of the information systems in the different facilities in HP has been mixed. While the frontline (public-facing) modules of registration and billing have found more regular and active use, it has been far more complex to get the doctors to use the clinical modules. The use of support modules such as for lab, stores, and drugs appear to vary with the enthusiasm and initiative taken by staff in particular roles in specific facilities. The intended beneficiaries of the project are, of course, the patients themselves. Therefore we now discuss some patient based views elicited through personal interviews with them. We also provide a brief description of the reaction of others to the system, such as doctors and nurses, since these have a direct impact on patient experiences.

\subsection{Perspectives of patients and others on benefits from HospIS to them}

The registration and billing modules were in active use at all facilities. The registration process was obligatory, with every patient required to go through it. Further, the billing module was obligatory as patients needed to pay to receive different services, such as X-rays and lab tests, before actually accessing them. At all facilities, data entry operators had been contracted to run the registration and billing modules. The medical superintendent and doctors in the hospitals seemed to be well aware of these modules, and how the computer generated 
information and reports from these modules could be used for further administrative functions, such as reviewing patient loads and getting daily billing figures.

59 out of 63 patients (94\%) felt that they had benefited from the registration module, as the registration slip which they received gave them the name, day, date, time and the Out Patient Department (OPD) room number they needed to visit. In the past, they would not know which room number to visit for their OPD consultation, requiring them to spend a lot of time asking for directions. The queues were more structured following computerization, and typically a patient would take 2 to 20 minutes waiting for their turn, and less than a minute to be registered and given the slip, while previously it was much longer. More orderly queues made life easier especially for senior citizens, women, and critical patients.

Being computer printed, the slip was easier to read, and with reduced errors of spelling of name or wrong noting of gender. 40 out of 63 patients (63\%) were happy that the doctor's name was not on the slip and that the room number was enough, because there was a frequent changing of doctors in the public set up. However, 42 out of 63 patients (67\%) did express their preference to get the slip in Hindi rather than in English. One patient said that he had travelled $200 \mathrm{~km}$ to get his mother treated. Now with the details he had on the slip, the next time around he could take his mother to a nearby facility and would not need to travel this long distance. Previously, 30 out of 63 patients (48\%) said that they did not get a very legible OPD slip from the doctor with a clearly written diagnosis. Now, having possession of a computer generated slip with details of the diagnosis and tests, the patient could potentially seek alternative opinions from other doctors/facilities.

With respect to billing, 42 out of 63 patients (67\%) expressed their happiness to receive a clear bill printout without calculation errors which helped them to apply for and receive reimbursement of expenses. However, as with the registration slip, most patients would have 
preferred to receive their bills in Hindi, which the system currently did not provide for. However one functionality that was popular was that, if a particular lab facility was not working, the billing clerk was advised about it through the system, allowing patients to avoid paying for the facility and then struggling later to get a reimbursement for a test not done.

The clinical modules of OPD and In Patient Department (IPD) were in general in a state of non-use across the hospitals. We saw long queues of patients for several OPDs like general, gynaecology, surgery, medicine and paediatric, while some others like dental and skin were not so busy. The common reason given by doctors for non-use of the system was that they were too busy and it was more important to spend time with the patient than with the computer. In some OPDs, computers were not functional, and often some parts (such as the mouse) had been misplaced leading to HospIS falling into non-use. Further, doctors felt using computers required skills and speed, and coming from a "transition generation" they were not so adept with computers.

In around $80 \%$ of cases, we found patients not aware that they should get the details of their encounter with the doctor (including diagnosis, follow up, lab reports, etc.) in a computer generated slip, and that they could access their details also in the future. We tried to encourage some of the patients we met to demand this slip from the doctor, and that it was their right given that significant public money had been invested in the system. The doctor's excuse of the lack of time was often non-tenable, and patient proactive demand could potentially help change the situation. Similarly, the IPD system was also in a state of limited to non-use, and we met no nurse using the system to admit or discharge a patient. Nurses normally attributed this situation to their heavy work load.

The situation in the laboratories was mixed across the hospitals. In labs where the system was being used, 16 out of 63 (25\%) of patients liked that they now got their results in a printed 
form, giving also test ranges for their reference. In general, it was seen that where lab technicians were not using the lab module, this was often due to their computer or printer being non-functional with difficulties in accessing support. With the heavy work load and limited manpower, it was difficult for them to focus on these issues of accessing timely support. Further, the lab technicians said that they have not been given clear and standing instructions to use the new system or to discontinue the paper records.

The use of the system by the pharmacists was limited for reasons similar to the lab technicians - high work load, non-functional computers, and no compulsory orders from the hospital management to use the system. It seemed to be a personal choice of the pharmacist to use or not the system, and we saw in some hospitals the system being used, and not in others. The use of the hospital pharmacy overall was limited, as only about $10 \%$ of the total patients actually went to the dispensary for drugs; typically they were very poor or were staff of the hospital. Further, most of the drugs prescribed by the doctors were not available at the hospital pharmacy. In general, patients had little experience with the system in the pharmacy. Although, if used, it would be possible for a patient to receive the benefits of a cleanly printed bill with named drugs and the associated ease of receiving refunds.

\section{CASE ANALYSIS: TECHNOLOGICAL, SOCIAL AND INSTITUTIONAL INNOVATION}

Our analysis of the case is divided into two sections. In this section, we discuss the HospIS project across the three dimensions of technical, social and institutional innovation. Table 1 summarises the contents of this section showing key characteristics of each type of innovation and related implications.

[Insert Table 1 about here] 


\subsection{Technological innovation}

With respect to technological innovations, HospIS utilised a free and open source software platform called OpenMRS. OpenMRS is a global leader in open technologies and open standards in health care (see openmrs.org for more details). INGO used the OpenMRS platform to build the HospIS system to fit the needs of Himachal Pradesh. Often the process is the other way around, where an expensive proprietary platform is procured, and a client is asked to fit into the demands of the application. A key focus of INGO's strategy was to concentrate on essential modules and features, and develop them through a strongly participatory and user driven approach. While OpenMRS is a globally used platform for building clinical systems, it had not been developed as an integrated hospital information system within a developing country context. INGO thus had the opportunity to work with a new platform, learn through trial and error, and create something truly "home-grown".

In the process of the 5-year period of design, development and implementation, INGO not only learnt about the technical systems, but also developed an intimate understanding of capacity building requirements at the individual and institutional levels. For example, they were able to demystify the technological complexities to coach and mentor a small and local data entry firm to perform higher level functions of training and support. This helped to develop local state-specific capacity and in the process reduced dependence on expensive external consultants.

\subsection{Social innovation}

Social innovation includes making improvements in the living conditions of people, especially those who are disadvantaged and disenfranchised. The population who visits district hospitals in India is typically from the poorer segments of society, as richer groups 
tend to opt for private care. Therefore, using HospIS to improve the experience of patients in a public hospital, or enhancing the quality of their care, will directly contribute to strengthen the social aspects of human functioning of the less privileged.

Various process improvements were made in the hospitals together with the introduction of HospIS. For example, the centralization of the billing function meant that the patient did not need to queue up in multiple lines to make payments for different services. In the earlier manual system, doctors would typically not give the name of the diagnosis, and would only write down the prescriptions in the OPD slip. HospIS made it mandatory for the doctor to enter a "provisional diagnosis" on the OPD slip. This is empowering for the patient, who can take this slip and get opinions from other doctors in other hospitals. HospIS potentially helped create richer medical records with historical patient information, especially useful for care of chronic diseases like TB, Diabetes and HIV. This potential was, however, not materialized with the doctors not using the system, citing high patient load as the reason for non-use.

Anyone who has visited a district hospital in India will be struck by the milling crowds waiting to get care. A typical hospital serves 600-800 patients a day, and each doctor would thus see 50-75 patients daily leading to the build-up of unruly queues at different points such as at registration, or in front of the doctor's office, the pharmacy and billing counters. Often, women, children, and old people who are not strong enough to take the pressures of the queues, are pushed behind, having to wait a long time before receiving service. HospIS managed to bring some structure to the queues, through, for example, the obligatory central registration module. Similar queuing systems were built in other parts of the system, such as billing and the laboratory.

HospIS created the potential for generating local entrepreneurship and capacity, and with it strengthen local ownership of systems. In the process of building and supporting HospIS, 
INGO built in-house capacity, and also tied up with other local entities in the state and trained them to carry out tasks like data entry, hardware support, and server maintenance. The case demonstrates a feasible business model of how local entrepreneurship can be made to work based on open source software in developing countries. HospIS also provided innovations that carried potential benefits for larger society. Coming without exorbitant license costs helped to conserve valuable tax payers' resources, and the system could be deployed in more peripheral rural health facilities and not just in the central state system. However, for the potential benefits to be materialized, it is necessary that the system be used, most importantly, by the doctors. This indeed was not yet the case. Further, given the conditions of widespread illiteracy amongst the rural population, patients were often not informed enough to demand from the doctors a copy of their clinical summary.

\subsection{Institutional innovation}

HospIS also enabled various institutional innovations. India invests less than $1.5 \%$ of its GDP in public health, which is grossly inadequate, and is reflected in the weak resources in health facilities which are dealing with high patient loads. Investments in ICTs also suffer, and most hospitals remain manual. These conditions adversely influence achieving the public goal of "health for all.” HospIS is based on an open source platform, does not involve involve expensive private sector vendors, and thus helps, to some extent, to address resource challenges and to reach out to rural populations. Further, HospIS potentially provides better information on patients, making visible geographical areas and patient categories needing improved care.

Himachal Pradesh needed to carry out institutional innovations to procure INGO’s services given typical restrictions in government procurement systems, based on a tendering process which is time consuming, bureaucratic, and subject to political interference. Similarly, 
innovations were carried out in not defining requirements as a starting point to the project, but as a key component of the project itself. Changing historically embedded institutional structures is a non-trivial challenge in contexts such as India. There is a need for improvisation, smart thinking, and most often the ability to show positive outcomes in order to create a momentum for change. The HospIS project managed to create some innovations to provide a space to act, and INGO duly responded by creating an effective state wide hospital IS infrastructure.

\section{CASE ANALYSIS: INNOVATION FOR HUMAN DEVELOPMENT}

HospIS generates certain types of information, touches particular groups of people, and carries inherent potentiality for change, all of which taken together helps to create choices that can contribute towards creating more positive development outcomes. Drawing from our empirical analysis we have identified the following three key themes which represent elements of more positive human development: strengthening processes to include the disadvantaged; empowering the patient; and, making communal voices count. Drawing on the theoretical framework presented earlier in the paper, we analyse these themes from a CA perspective. Table 2 summarizes elements of this analysis, and they are elaborated on in the text that follows.

[Insert Table 2 about here]

\subsection{Strengthening processes to include the disadvantaged}

HospIS is designed for supporting work in health facilities which are primarily mandated to provide health care to the rural population, who have historically been at the receiving end of 
weak systems of care. Traditionally, health systems in India are controlled by the state, and districts and sub-district facilities play the role of implementing the state schemes. HospIS was deployed at the district level, enabling better access to health care resources at the district level. This can potentially be converted to capabilities for the patients to demand better outreach care, as now HospIS is recording referral information for each patient including details such as which health facility jurisdiction the patient is coming from, for what kind of treatment he/she is being referred, and the poverty and other relevant demographic status of the individual. However, for these capabilities to be effectively realized, and in turn produce the functioning of healthier patients, administrators at the district hospital must systematically analyze this referral information, identify which facilities and specializations are weak, and take necessary actions to plug these gaps in primary and outreach care.

This potential for ICTs to include the disadvantaged in development processes has been powerfully argued for by Castells (1996). He writes that including disadvantaged people and areas in the "network society" can provide a vehicle to redress some of the on-going tendencies of systemic marginalization. Disadvantaged groups will continue to be marginalized if their conditions remain black-boxed and not visible to those in power who are responsible for making health policy and providing resources and interventions to change these conditions. Information enabled through processes of the network society provides a powerful vehicle to break these conditions which reinforce marginalization. The collection, analysis and action taking processes of referral information enabled by HospIS provide a concrete vehicle for the disadvantaged rural population to be better included in the 'network society'.

Challenges in establishing the referral network may start with the data entry operator not recording correctly the referral information, administrators not looking at the analysis, and 
subsequently not acting on it or not having adequate resources (time, travel allowance to the health facilities) to do the needful. There can be other inhibiting conditions such as weak political will, poor informational competencies (to interpret and analyze the information) or vested interests in play to maintain the status quo. Both doctors and patients need to be informed of the value of strengthening these informational networks, and patients encouraged to demand this as their right to better and affordable care for the present and future.

A specific example of 'strengthening processes to include the disadvantaged' which has already been achieved to some extent in the case example concerns the issue of queues. As noted earlier in the paper, there are normally thronging crowds at a district hospital, especially at counters of registration, and the busy OPDs of maternal and child health. In the absence of a system to structure the queues, the crowds would each try their particular ways of reaching up front - pushing, using personal connections with the clerk at the door, or sometimes offering a bribe. It can often be a story of "survival of the fittest”, and senior citizen, children, women, and sick folks would mostly be disadvantaged by having to wait longer and experiencing more inconvenience than able-bodied. The long and unruly queues are a characteristic of the health goods/services as offered by the hospital, which really hamper access to health care for disadvantaged groups. This implies that for certain categories of people there are personal conversion factors that make it harder for them to realize valuable capabilities of being healthy. The ICT-based innovation in the case example changed the characteristics of goods/services (structuring, reducing time), and created new goods/services (like the diagnosis slip) and, in so doing, it helped to reduce some of the hampering personal conversion factors for the disadvantaged to attaining desired capabilities. 


\subsection{Empowering the patient}

Ruger (2010) addresses the issue of what constitutes 'health capability' and argues that it involves both good health (health outcomes) and the ability to pursue it (health agency). The previous discussion of systems to structure queues in ways to help the disadvantaged obtain better health outcomes is an example of the former. This sub-section discusses the latter, through the example of active patient agency on treatment choice. Choice of treatment, including which doctor, hospital and location, is an important informational capability for empowering the patient. The medical record is a resource to support this choice, and was in a manual form prior to the introduction of HospIS. This manual record typically did not specify the (provisional) diagnosis, and only gave the names of drugs or prescriptions prescribed to the patient, often in rather illegible handwriting. As a result, the patient was locked to the particular doctor and facility since the record was not easily transportable. The electronic medical record generated by HospIS was potentially an answer to this problem, as it included a provisional diagnosis (which was now a mandatory field), and details of prescriptions, procedures and follow up action. This longitudinal record, available in computer printed forms, then becomes a concrete vehicle for the patient to get enhanced choices and makes him/her better informed about their health status and line of treatment. Furthermore, since the medical record contains all historical information (such as details of test results, OPD and IPD encounters, drugs prescribed, etc.) all in one place, the patient need not run to different places for different pieces of the treatment information. Additionally, each of these pieces of information is richer than before - for example, the lab tests contain reference ranges and the ultrasound images have the technician's notes. 
The biggest obstacle to achieve this enhanced capability for treatment choice by patients, and in turn for the functioning of better treatment, has been the deep reluctance of the doctors to use the system, implying key clinical information is not being captured in the medical record. The doctors have many explanations for this non-use. On days when OPD is busy, a doctor may see 50-75 patients in a 4 hour time slot, which gave them about 2-3 minutes with each patient. In this short time, the doctors felt it was not possible to talk to the patient, provide the required care and also fill in the electronic record. There were often power outages, which meant that the doctor could not access the record while the patient was across the table. Some doctors described themselves as belonging to a "transitional generation" where they were not adequately oriented to computer working. These challenges of doctor non-use of electronic medical record (EMR) systems are indeed not specific to this case study, but represent a wider problem in hospital information systems from both developed and developing countries (Mukherjee et al 2012).

How can these challenges be addressed is a non-trivial question. It would require policy directives where systems are in some way made obligatory and not left to the wishes of the individual doctor. Asking doctors to focus on chronic patients (such as TB, HIV or Diabetes) for the generation of the electronic record, and to not do so for the higher percentage of patients coming in for episodic treatment of common ailments like fever and fractures, may be an approach to help reduce some of the workload of doctors. Building awareness and capacity amongst patients to demand their electronic medical record as their basic citizen-based rights, could also help to place pressure and consciousness amongst doctors to create and use the record.

\subsection{Making communal voices count}


The previous two sub-sections on helping the disadvantaged and empowering patients reflect the emphasis of the capability approach on the individual and how to enhance his or her their health outcomes and health agency. However, groups and other collective forms are clearly important. Stewart (2005) argues that groups are a direct source of well-being (or ill-being), are a mechanism for the enlargement of individual capabilities, and are a strong influence over preferences as to which capabilities individuals value. Ibrahim (2006) argues that the capability approach needs to be complemented by concepts and theories of collective action, institutions and social capital.

Within the public health system of developing countries, the focus is indeed primarily on communities and population based care. While HospIS is a patient focused system, it can be systematically aggregated to develop community-based profiles such as of mortality and morbidity including leading causes of death. Such profiles, accurately compiled, can help administrators to focus attention on diseases and areas where they are needed most. Individual voices can thus be collectively organized to make them count in improving care. HospIS serves in two ways as an important mediating influence on this process towards effective functioning of patients with respect to being better informed on community focused health concerns. Firstly, it helps to generate the individual record of a patient including details of the community he/she belongs to. Secondly, it aggregates these records to create community health profiles, for example the ten top diseases. Challenges to achieving this functioning comes from the incomplete nature of the medical record, poor analysis, and limited dissemination of information to important community functionaries such as village political representatives.

Historically, the rural population in India has limited possibilities to articulate their voices in shaping health care to them through the public health system. While the Indian Constitution 
delegates health care as a state subject, health care programmes and delivery takes place through a strongly centralized model. Rural populations can be held hostage to the doctors in the facilities, who often run their private practice at the expense of their commitment to the public system where they are legally employed. As a result, many patients have lost trust in the public health system, and if they can afford it tend to seek care in the more expensive (and sometimes unscrupulous) private system. Those who can't afford the private sector will either resign themselves to get what they can from the public system or visit quacks and traditional medicine practitioners.

Centrally, the Indian government established the National Rural Health Mission (NRHM) in 2005, seeking to make systemic corrections in the public health system and to restore the trust of people in it. Decentralization of systems, including information systems, was seen as a key vehicle for enabling these corrections, as it would allow the health department to come closer to the people, be able to hear their voices, and try to make these voices count in shaping health care delivery. Despite these aims, often the information systems developed by the government remain highly centralized, and contrary to the decentralization aims. HospIS was consciously designed by the state of HP with these aims of decentralization in mind, through two key vehicles. One, by covering all the hospitals in the state and ensuring referral information is collected (and subsequently analyzed and used) from all the population residing in the catchment area of the hospital. Two, by collecting patient specific (not just facility based) data which helps to make the condition of individuals in the collective context of the community more visible.

\section{CONCLUSION}


We noted in the Introduction to this paper that a major challenge for researchers is to theorize the link between ICT-based innovation and human development. We have addressed this challenge in the paper as follows. We have used a case study of a hospital information system in a particular Indian state as an illustration of three types of innovation: technological social, and institutional. We have then asked the question as to how the ICT-based innovation contributes to human development. We have drawn on the capability approach of Sen to conceptualize an answer to this question through theories of increased freedoms and choices brought about for participants. We have illustrated how the hospital information system in the case study led to increased opportunities for choice for the patients in public health systems, who are relatively poorly served at the present time in most parts of India. We have discussed some of these opportunities under the themes of strengthening processes to include the disadvantaged, empowering the patient, and making communal voices count. We have discussed positive outcomes from the work to date but we have also identified challenges that remain in order to fulfil the full potential of the ICT-based innovation in this context.

A key contribution of the paper is, therefore, a detailed and rich case study involving ICTs, innovation and human development. We also would argue that the theoretical framework we have used may be of value in other contexts where technology is being used in an innovative way to enhance human capabilities and functionings. Our approach is consistent with some recent literature in this particular field. We noted earlier in the paper that our framework incorporates innovation and adds a dynamic element to the standard capability approach, as advocated by Hartmann (2012). In addition, our framework, in addressing the role of technology in expanding human capabilities, integrates technology with broader social and institutional structures, as called for by Oosterlaken (2011) and Ziegler et al (2013). We have 
also noted links of our study with the literature (Stewart 2005, Ibrahim 2006) on the capabilities of groups and other collectivities.

Finally, it is worth noting one limitation of our study which also leads to further research opportunities in the future. Our case stopped at the point at which some improvements in patient care, such as more orderly queues and enhanced choices, are now available to patients in this particular Indian state. However, will the information systems result in major changes in capabilities for choice in the future and enhanced functionings such as significantly improved health for patients? We obviously hope so, but further research is needed to provide empirical evidence for this, involving the full range of human stakeholders, so that we can strengthen our claim that ICT-based innovation can contribute to improved human development outcomes.

\section{REFERENCES}

Avgerou, C. (2010) 'Discourses on ICT and development', Information Technologies and International Development, 6(3), pp. 1-18.

Bhatnagar, S.C., and Bjørn-Andersen, N. (eds) (1990) Information Technology in Developing Countries, North-Holland, Amsterdam.

Bhatti, Y. (2012) 'What is frugal, What is innovation? Towards a theory of frugal innovation', Working Paper, Said Business School, University of Oxford. http://ssm.com/abstract=2005910.

Braa, J. and Sahay, S. (2012) Integrated Health Information Architecture : Power to the Users, Matrix Publishers, New Delhi.

Castells, M. (1996) The Rise of the Network Society, Blackwell, Oxford. 
Drèze, J. and Sen, A. (2013) An Uncertain Glory: India and its Contradictions, Princeton University Press, Princeton, NJ.

Hartmann, D. (2012) 'Sen meets Schumpeter: Introducing structural and dynamic elements into the human capability approach’, FZID Discussion Paper, No. 48, http://nbnresolving.de/um:nbn:de:bsz:100-opus-7241

Hattaka, M., and Lagsten, J. (2012) 'The capability approach as a tool for development evaluation - analyzing students' use of internet resources', Information Technology for Development, 18(1), pp. 23-41.

Heeks, R. (2006) ‘Theorizing ICT4D research’, Information Technologies \& International Development, 22(5), pp. 1-4.

Heeks, R. (2010) 'Do information and communication technologies (ICTs) contribute to development?', Journal of International Development, 22(5), pp. 625-640.

Ibrahim, S.S. (2006) 'From individual to collective capabilities: The capability approach as a conceptual framework for self-help', Journal of Human Development, 7(3), pp. 397416.

Kleine, D. (2010) 'ICT4What? - using the choice framework to operationalise the capability approach to development', Journal of International Development, 22(5), pp. 674-692.

Kleine, D. (2013) Technologies of Choice? ICTs, Development, and the Capabilities Approach, MIT Press, Cambridge MA.

Latour, B. (2005) Reassembling the Social: An Introduction to Actor-Network-Theory, Oxfor University Press, Oxford.

Moraczynski, O. (2009) 'Exploring the usage and impact of 'transformational' mobile financial services: the case of M-Pesa in Kenya', Journal of East African Studies, 3(3), pp. 509-525.

Mukherjee, A.S., Sahay, S., and Aanested, M. (2012) 'Judicious design of electronic health records: Case from public health system in India', Health Policy and Technology, 1(1), pp. 22-27. 
Oosterlaken, I. (2011) 'Inserting technology in the relational ontology of Sen’s capability approach', Journal of Human Development and Capabilities, 12(3), pp. 425-432.

Pralahad, C.K., and Hammond, A. (2002) ‘Serving the world’s poor, profitably’, Harvard Business Review, 80(9), pp. 4-11.

Robeyns, I. (2005) 'The capability approach: a theoretical survey’, Journal of Human Development, 6(1), pp. 93-117.

Ruger, P.R. (2010) ‘Health capability: Conceptualization and operationalization’ American Journal of Public Health, 100(1), pp. 41-49.

Sen, A. (1999) Development as Freedom, Oxford University Press, Oxford, UK.

Smith, M.L., Spence, R., and Rashid, A.T. (2011) 'Mobile phones and expanding human capabilities’, Information Technologies \& International Development, 7(3), pp. 77-88.

Stewart, F. (2005) 'Groups and capabilities’, Journal of Human Development, 6(2), pp. 185204.

Zheng, Y. (2009) 'Different spaces for e-development: What can we learn from the capability approach?’, Information Technology for Development, 15(2), pp. 66-82.

Zheng, Y., and Walsham, G. (2008) 'Inequality of what? Social exclusion in the e-society as capability deprivation”, Information Technology \& People, 21(3), pp. 222-243.

Ziegler, R., Karanja, B.H.K., and Dietsche, C. (2013) 'Toilet monuments: an investigation of innovation for human development, Journal of Human Development and Capabilities, 14(3), pp. 420-440. 


\begin{tabular}{|c|c|c|}
\hline $\begin{array}{l}\text { Domains of } \\
\text { innovation }\end{array}$ & Key characteristics & Implications \\
\hline Technological & $\begin{array}{l}\text { Based on open source and free } \\
\text { platform } \\
\text { Keeping primary focus on what } \\
\text { is essential and feasible based } \\
\text { on a participatory approach } \\
\text { Strongly grounded in local } \\
\text { support }\end{array}$ & $\begin{array}{l}\text { No cost of licence; owned by the State, } \\
\text { with potential for future evolution } \\
\text { Providing immediate benefits to users } \\
\text { and end-beneficiaries } \\
\text { Reducing dependency on expensive } \\
\text { external consultants }\end{array}$ \\
\hline Social & $\begin{array}{l}\text { Strengthening trust in the } \\
\text { public health system } \\
\text { Improving patient experience } \\
\text { in the hospital } \\
\text { Nurturing local } \\
\text { entrepreneurship capacity }\end{array}$ & $\begin{array}{l}\text { Will help to strengthen demand side for } \\
\text { better health care. } \\
\text { Will motivate patients to use public } \\
\text { system, and away from the expensive } \\
\text { private providers which they can ill- } \\
\text { afford } \\
\text { Creating alternative business models } \\
\text { based on open source software }\end{array}$ \\
\hline Institutional & $\begin{array}{l}\text { Enabling extended institutional } \\
\text { reach to rural and marginalized } \\
\text { populations } \\
\text { Based on new systems of } \\
\text { procurement of IT solutions in } \\
\text { the public system }\end{array}$ & $\begin{array}{l}\text { The state has improved information on } \\
\text { where they need to focus most to } \\
\text { improve health. } \\
\text { Creating a precedent of procuring an } \\
\text { open source based IT solution; } \\
\text { providing for alternative models of } \\
\text { system development and use for the } \\
\text { rest of the country }\end{array}$ \\
\hline
\end{tabular}

Table 1 Key Features of Innovation in the HospIS Project 


\begin{tabular}{|c|c|c|c|c|}
\hline Theme & $\begin{array}{c}\text { Goods and } \\
\text { Services }\end{array}$ & Capabilities & $\begin{array}{c}\text { Mediating } \\
\text { Influence of } \\
\text { Hospls }\end{array}$ & Challenges \\
\hline $\begin{array}{c}\text { Including the } \\
\text { disadvantaged }\end{array}$ & $\begin{array}{c}\text { Access to } \\
\text { health care } \\
\text { at district } \\
\text { level }\end{array}$ & $\begin{array}{c}\text { Better care/ } \\
\text { healthier } \\
\text { patients }\end{array}$ & $\begin{array}{c}\text { Better access (e.g. } \\
\text { orderly queues); } \\
\text { capture of referral } \\
\text { information }\end{array}$ & $\begin{array}{c}\text { Analysis of } \\
\text { referral } \\
\text { information not } \\
\text { carried out }\end{array}$ \\
\hline $\begin{array}{c}\text { Empowering } \\
\text { the patient }\end{array}$ & $\begin{array}{c}\text { Medical } \\
\text { records }\end{array}$ & $\begin{array}{c}\text { Choice of } \\
\text { treatment }\end{array}$ & $\begin{array}{c}\text { Producing and } \\
\text { making available } \\
\text { medical records to } \\
\text { patients }\end{array}$ & $\begin{array}{c}\text { Limited use by } \\
\text { OPD doctors }\end{array}$ \\
$\begin{array}{c}\text { Making } \\
\text { communal } \\
\text { voices count }\end{array}$ & $\begin{array}{c}\text { Visibility of } \\
\text { medical } \\
\text { condition in } \\
\text { community }\end{array}$ & $\begin{array}{c}\text { Bemmunity } \\
\text { focused care }\end{array}$ & $\begin{array}{c}\text { Ability to provide } \\
\text { morbidity and } \\
\text { mortality profiles on } \\
\text { communities }\end{array}$ & $\begin{array}{c}\text { Analysis reports } \\
\text { not sent to } \\
\text { community } \\
\text { functionaries like } \\
\text { the village } \\
\text { political body }\end{array}$ \\
\hline
\end{tabular}

Table 2: Summary of Analysis of Human Development Themes 


\section{Patient Name}

Age

Gender

\section{OPD Name}

\section{Patient Status}

\section{Part I: About the patient}

1.1 Whether first time or repeat patient

1.2 Distance from the main hospital

1.3 Cost of travel to the main hospital

1.5 Whether from BPL category

Part II: About the patient experience in the hospital (for Revisit patients)

\section{Registration}

2.1. Have patients benefitted from room no in registration slip

2.2. Would it be useful to get name of the doctor

Billing

2.3 How useful it is to get a clearly printed bill

2.4 Any additional information they would like

OPD

2.5 Has the doctor used the computer to enter the consultation details

2.6 Did you know the doctor should use that? You must demand that

2.7 Give benefits of having your details in the computer - revisit, full details, historical data etc Laboratory/Radiology

2.8 Do you get computerized Lab reports

2.9 When you go to the doctor for consultation, does he see your investigation results on the computer or hard copies 2.10 Did you know that doctor can see your Investigation results on his computer? You must demand it.

\section{Pharmacy}

2.11Does the pharmacist uses his computer to give you drugs

2.12 When you go to the doctor for consultation, does the doctor check in his computer what drugs you have been given at the pharmacy

2.13 Did you know that doctor can see what drugs have been issued to you at the Pharmacy on his computer? You must demand it.

\section{Indoor Patient Department}

2.14 Does the nurse use her computer to admit you and assign a bed in a ward

2.15 During discharge, does the nurse use the system

2.16 Average time taken in different queues (registration, OPD, billing, others)

2.17 Nature of the queues, are they more structured, orderly and less time taking than before?

2.18 Does the doctor seem to provide more, and qualitatively better time to the patient?

2.19 Does the patient now get improved and richer documentation of his/her medical condition, such as lab reports, OPD slips, bills, and other document?

2.20 Does he/she experience a better "patient-friendly" environment in the hospital, for example ease in getting refunds, better

\section{Part III : About patient choices}

3.1 Does the OPD slip which the patient gets, provide more choices to them to get consultations and services from other doctors and facilities?

3.2 Is there now more information available on alternative choices available for services, such as kinds of meals and hospital beds? 
3.3 Does understanding of costs and quality of services provide choices to patients to seek services elsewhere, such as their local health clinic?

3.4 Has the integrated and historical medical record helped the patient to get his/her medical record in one place when it is required?

3.5 Armed with the medical information, is the patient more knowledgeable about asking more questions about the state of his/her health?

\section{Part IV: Do patient voices count?}

4.1 Is the patient able to discuss his/her experience with the hospital with fellow community members? Does it lead to the development of a louder voice?

4.2 Are there opportunities to express opinions about the hospital/system?

4.3 Are there opportunities to express views about services offered? Such as OPD care, availability of drugs, lab testing etc?

4.4 Does anyone from hospital seek opinions about patient experiences in hospitals?

4.5 In future, the potential seen of the system to amplify patient voices?

Part V: For repeat patients

5.1 Why did you decide to come to this hospital?

5.2 What are the other health facilities you have used in the past 